\title{
NOTAS AL PIE DE GAZA (2009), DE JOE SACCO: REPRESENTACIÓN DEL CUERPO Y SU ROL CENTRAL COMO TESTIMONIO
}

\author{
JOE SACCO'S FOOTNOTES IN GAZA (2009): \\ REPRESENTATION OF THE BODY A \\ ND ITS CENTRAL ROLE AS TESTIMONY
}

\author{
Mary MAC-MILLAN \\ Universidad Adolfo Ibáñez de Chile \\ mary.macmillan@uai.cl
}

\begin{abstract}
Resumen: En este artículo analizamos la novela gráfica de Joe Sacco Notas al pie de Gaza (2009) centrándonos en las diversas representaciones del cuerpo. Sacco aborda una compleja investigación sobre dos matanzas cometidas por el ejército israelí sobre la población palestina de la Franja de Gaza en el año 1956. Distinguimos tres usos del cuerpo, los que aportan directamente a la fuerza testimonial del relato: la fórmula cinegética, el cuerpo como cohesión social y el cadáver como persistencia.
\end{abstract}

Palabras clave: Joe Sacco. Cuerpo. Cadáver. Masacre.

Abstract: In this article we analyze the graphic novel by Joe Sacco Footnotes in Gaza (2009), focusing on the different representations of the body. Sacco addresses a complex investigation into two massacres committed by Israel's armed forces on the Palestinian population of the Gaza Strip in 1956. We distinguish three uses of the body, which directly contribute to the testimonial force of the story: the hunting formula, the body as social cohesion and the corpse as persistence.

Key Words: Joe Sacco. Body. Corpse. Slaughter. 


\section{INTRODUCCIÓN}

La obra de Joe Sacco ${ }^{1}$ ha ido captando progresivamente el interés crítico y académico. Sus dos novelas gráficas centradas en el conflicto palestino-israelí (Palestina y Notas al pie de Gaza) permiten una reflexión de varios tópicos sumamente actuales. Tales como la representación de la violencia, el testimonio gráfico y la posibilidad de asumir la voz de los silenciados. Sacco ha creado un estilo gráfico fácilmente reconocible y de gran madurez al interior del género de la novela gráfica. A diferencia de muchos autores que sobresalen tan sólo por una obra testimonial inicial y posteriormente decaen, Sacco profundiza y radicaliza su obra. Eso es claramente lo que ha sucedido entre Palestina y Notas al pie de Gaza. En relación a las aproximaciones críticas se le suele adscribir dentro de la problemática del trauma. A modo de ejemplo podemos citar a Harriet Earle con su libro: Comics, trauma, and the new art of war y a Andrés Romero-Jódar con The trauma graphic novel. Lo traumático en Sacco se refiere a los acontecimientos bélicos que suele tratar en sus obras: masacres, bombardeos, violencia y represión diaria. Nuestra aproximación a su trabajo gráfico se realiza desde cuestionamientos éticos: el posible rol de la identificación en una toma de conciencia o una nueva humanización del otro desde la asunción de una vulnerabilidad común. Mencionamos a continuación algunos artículos que están en sintonía con esta lectura. De Rebecca Sherr: "Framing human rights: comics form and the politics of recognition in Joe Sacco's Footnotes in Gaza"; de Maureen Shay: "Framing refugee time: perpetuated regression in Joe Sacco's Footnotes in Gaza" y "Complicities of Witnessing in Joe Sacco's Palestina" de Wendy Kozol. Ahora bien, y ya explicando el enfoque de este trabajo, creemos que la función del cuerpo en relación a la experiencia traumática aún no ha sido abordada. Postulamos la centralidad del cuerpo como espacio en el que ocurre el acontecimiento traumático.

\footnotetext{
${ }^{1}$ Joe Sacco es un reconocido periodista norteamericano de origen maltés (1960). Es autor de numerosas novelas gráficas entre las que se destacan: Gorazde: Zona Protegida. La Guerra en Bosnia oriental (2000), La Gran Guerra (2013) y Palestina. En la Franja de Gaza (2004). Por Palestina recibe el Premio American Book Awards. Para una mirada general a su obra recomendamos The Comic of Joe Sacco. Journalism in a visual world (2015), editado por Daniel Worden. Sobre su método de trabajo hay varios artículos bien descriptivos: "Joe Sacco on Footnotes in Gaza" (2011) de Gary Groth, "Reconsidering Comics Journalism: Information and Experience in Joe Sacco's Palestine" (2010) de Benjamin Woo y "The New Journalism Revisited" (2007) de Rocco Versaci.
} 
En el presente trabajo nos abocaremos al análisis de la novela gráfica de Joe Sacco titulada Notas el pie de Gaza (2009). En Notas, Sacco se sumerge una vez más en el complejo mundo de la Franja de Gaza y el conflicto palestino-israelí. En esta ocasión irá en busca de testigos que le permitan reconstruir dos trágicos hitos dentro del ya largo conflicto bélico mencionado: las matanzas de Rafah y Khan Younis. Ambos sucesos datan del 1956 y fueron perpetrados por soldados israelíes sobre la población civil masculina. Nos interesará dar cuenta del rol que el cuerpo asume y las diversas representaciones elaboradas por Sacco. Proponemos tres usos del cuerpo, los que apoyarían la finalidad testimonial y de denuncia de Notas $^{2}$. El primer uso lo hemos denominado, basándonos en la nomenclatura de Burucúa y Kwiatkowski, como la fórmula cinegética, y se refiere a las analogías entre cuerpo y animal presentes en el segundo capítulo. El segundo uso del cuerpo se liga a las teorías de Judith Butler acerca de la importancia de la corporalidad como ente estructurador social y de resistencia. Por último, nos referiremos al cuerpo cadáver y la fuerza que éste irradia al interior de los testimonios recogidos por Sacco. En síntesis, mostraremos cómo en la representación gráfica testimonial de Sacco el cuerpo ocupa un rol preponderante.

\section{CUERPO Y FÓRMULA CINEGÉTICA}

José Emilio Burucúa y Nicolás Kwiatkowski, en “Cómo sucedieron estas cosas". Representar masacres y genocidios (2014), postulan la existencia de determinadas fórmulas de representación. En relación a diversos hechos históricos tales como masacres y genocidios, existirían fórmulas básicas a las que se echaría recurso una y otra vez: "Una fórmula de representación es, entonces, un conjunto de dispositivos culturales que han sido conformados históricamente y, al mismo tiempo, gozan de cierta estabilidad, de modo que son fácilmente reconocibles por el lector o el espectador" (2014: 46). Los autores distinguen tres fórmulas: la cinegética, la del infierno y la del martirio. Estas fórmulas "son metáforas complejas que definen y representan hechos (las masacres reales) mediante la indicación de otros hechos (la caza, el infierno, el martirio)"(2014: 71). Nos

\footnotetext{
${ }^{2}$ En otro artículo hemos abordado este tema. Ver: "Notas al pie de Gaza de Joe Sacco: un historiador a contrapelo (anacronía y memoria)" (Mac-Millan, 2019).
} 
centraremos en la fórmula cinegética y su modalidad concreta en Notas al pie de Gaza. Notas es un libro complejo en términos estructurales. Consta de un prólogo, tres capítulos y termina con un apéndice. Los tres capítulos se titulan sucesivamente: Khan Younis, Festín y Rafah. El capítulo 1 y 3 están directamente relacionados con la investigación central que guía la novela: las matanzas. Sin embargo, el segundo capítulo ("Festín"), notoriamente más breve, parece no calzar del todo con los otros dos. Es una pausa o digresión en relación a la investigación y a los testimonios recopilados. Proponemos una lectura de "Festín" desde la centralidad del cuerpo y el recurso a la fórmula de representación cinegética. La fórmula cinegética se relaciona con la cacería: "la cacería ha sido utilizada como una fórmula para la representación de masacres humanas desde la Antigüedad clásica" (2014: 50). Sin embargo, la fórmula no se restringe exclusivamente a la metáfora de la cacería, sino más bien a todo recurso de animalización. Citamos a Burucúa y Kwiatkowski: "el sufrimiento animal como metáfora del sufrimiento humano tiene un peso indudable en los intentos actuales de representar nuevas masacres" (2014: 200). La animalización puede fungir hacia ambos lados, tanto hacia la víctima como hacia el victimario. El sufrimiento animal sirve para dar una nueva dimensión al sufrimiento humano: "la fórmula está cargada de sentidos que llevan un efecto aparentemente paradójico, pues como hemos visto algunos brutos eran considerados víctimas inocentes de sus cazadores, de modo que la inhumanidad y la crueldad revierten sobre estos" (2014: 65). Así, los autores identifican dos tipos de animalización: una que condena la violencia brutal de los perpetradores y otra que realza la inocencia redentora de la víctima. Creemos que la metáfora cinegética de "Festín" actúa en Notas en este doble movimiento: los palestinos son inocentes como el toro sacrificado a vista y paciencia de todos y los israelíes son brutales y crueles. En apariencia extemporáneo con el eje investigativo, el "Festín" (2009: 137-145) debe leerse en profunda conexión con las dos masacres que recorren toda la novela gráfica.

"Festín", mencionábamos, implica una pausa en el proceso investigativo de Sacco y también en la estricta dominancia política y de contingencia en el conflicto Palestino-Israelí. Nuestra lectura apunta a mostrar cómo esta pausa o desconexión lo es solo en apariencia, ya que mediante la fórmula cinegética, todo el fragmento se vuelve una representación más de la masacre del pueblo palestino. Sacco mismo 
parece dar la clave del festín como una pausa: "Hemos pospuesto nuestra investigación por unos días. Nadie quiere hablar de 1956 en Eid El-Adha, el festín que conmemora la decisión de Abraham de sacrificar a su hijo Ismael a Alá" (2009: 137). Ahora bien, la lectura cinegética es sugerida inicialmente en el texto mismo en un diálogo que Sacco sostiene con un miembro de la familia que ha comprado un toro: "nosotros sacrificamos toros y Sharon nos sacrifica a nosotros" (2009: 139). Hay todo un uso de semas que asemejan las matanzas de los toros con las matanzas de Khan Younis y Rafah: sangre, carnicero, matanza, sacrificio. Siguiendo a Burucúa y Kwiatkowsky hay un nexo originario entre el carnicero y las masacres históricas en general: "el término masacre fue utilizado por primera vez en el sentido actual en Francia, en el siglo XVI. Hasta 1540, se lo había empleado para designar el lugar donde el carnicero cortaba las piezas; el cuchillo del carnicero se llamaba massacreur" (2014: 60-61). En el festín, la figura del carnicero será central. La ceremonia comienza con la compra de un animal por parte de una familia. El animal es conducido por la calle hasta su lugar de espera o encierro. Luego, aparece la figura del carnicero, hombre especializado en matar y dividir al animal. La conexión entre la matanza del toro y las masacres de Khan Younis y Rafah parte de la figura misma del carnicero y su enorme cuchillo como ente de acción. En el caso de "Festín", queda claro que matar a un toro no es fácil, de ahí que se necesiten, además del carnicero, varios hombres que toman parte de la ceremonia. Una vez que el animal ha muerto, se comienza el desmembramiento de éste por partes: primero se le corta la cabeza, luego las patas a la altura de las rodillas y se le extraen los órganos. El estómago y los intestinos se tiran a la acera, el bazo es arrojado "a la calle como si fuera una granada" (2009: 142). El pellejo es donado a un enfermo. Luego de esta división inicial el animal es troceado en partes más pequeñas y repartido en bolsas para cada una de las familias involucradas en la compra:

Han separado la carne en montones según las diferentes partes del animal y luego la cortan en pedazos más pequeños. Dividen los pedazos en siete porciones iguales, una para cada hogar. En presencia de todas las cabezas de familia [....]. Pero no acaba ahi. Cada hogar dividirá en más partes su porción: un tercio para la familia; otro tercio se repartirá en familiares cercanos y amigos; $y$ el otro para los pobres (144-145). 
Todo el proceso es en su totalidad presenciado y ejecutado por hombres, sólo en la parte final de la repartija más pequeña aparece recién la mujer y se vincula a la donación a los pobres. La ceremonia se da por terminada con una cena en la que Sacco y Abed, su guía, comen de la carne del toro. Abed hace una broma en relación a las entrevistas de Sacco sobre las matanzas y los toros: "Abed me dice que debería entrevistar a los toros sobre su masacre" (2009: 145). Nueva referencia interna a la cinegética. Sacco termina este capítulo con una viñeta que muestra la calle desolada y oscura, la fuerte lluvia cayendo y en una de sus escasas líneas de sugerencia poética se lee: "Mientras los bombarderos israelíes rugen invisibles a ras de suelo, la lluvia limpia la sangre de las calles" (2009: 145). Es decir, la pausa ha terminado, la violencia del conflicto bélico diario continúa.

Muchos son los elementos analógicos a mencionar entre la matanza del toro y las matanzas de 1956. Toda la faena pertenece a un mundo masculino y es de una crudeza visual casi insoportable. Los animales son machos, al igual que los hombres sacrificados en las matanzas. La escena es abierta a un sinnúmero de testigos tanto pasivos como activos. La matanza del animal ocurre a plena luz del día, toma varias horas y su lugar es principalmente la calle. Los animales son "pacientemente arrastrados por las calles de Khan Younis" (2009: 137), al igual que los palestinos asesinados conducidos por Sea Street. Todo el desmembramiento del animal es visualmente registrado por Sacco en viñetas sucesivas casi intolerables por el nivel de violencia y sangre. Para un lector occidental, al cual se le oculta el sufrimiento animal, la participación social de esta matanza choca por la tranquilidad que muestran sus participantes. Los niños, que "juegan" con la sangre que corre por las calles, aumentan el malestar: "ríos de sangre corren por las calles y los chavales usan el pringue para dejar en las paredes las huellas de sus manos" (2009: 139). La conexión entre la matanza del toro y las víctimas palestinas se exacerba visualmente mediante viñetas de cuerpos desmembrados que el lector ha retenido y que son notoriamente semejantes. Notable es la viñeta a tres cuartos de página con visión desde lo alto en que el cuerpo del toro yace mutilado sin cabeza y sin patas y los hombres continúan trabajándolo sin pausa ni asombro. Estas viñetas ya las hemos visto, pero con seres humanos como centro de violencia: mutilación de manos, brazos, cuerpos, troncos (2009: 81, 91). La sangre como un río que corre por el suelo de las calles también es una imagen frecuente (2009: 
95). La mostración de los órganos internos también refuerza la relación animal-víctima palestina. Un hecho resulta más complejo de leer en este recurso a la animalización. Ya hemos mencionado la exposición de esta matanza, en la medida en que ocurre en un espacio abierto como la calle y en que participan muchos miembros. Pero además es un fenómeno que abarca a la sociedad ya que toda la familia recibe partes del toro sacrificado. Todos se hacen parte de este sacrificio: algunos reciben más, otros menos. Así también puede entenderse el sufrimiento por las pérdidas de las víctimas en las matanzas perpetradas por los israelíes. El llanto o el dolor es algo que compete a toda la sociedad en la medida en que en casi toda familia hay pérdidas. Así como se reparte la carne del animal en trozos que terminan siendo consumidos por gran cantidad de miembros, así también las pérdidas humanas se reparten hasta las más diversas familias. En la repartija de las matanzas cada familia recibe su parte de dolor, su parte de cuerpo desmembrado y mutilado. La notable viñeta muda a doble página en la que hombres y mujeres buscan en medio de la noche su cadáver respectivo se convierte en un festín al revés (2009: 348-349). De partes diseminadas por el despoblado, ahora el pueblo busca reformar y aunar lo desmembrado en la ceremonia de la sepultura: "llegamos a la zona de la matianah", "había muchos cuerpos, muchos grupos de cuerpos", "un grupo aquí, un grupo allá, dondequiera que el camión había dejado los cuerpos", "los dejaron igual que si fueran pescado" (vuelve la fórmula cinegética) (2009: 350). El esfuerzo de las familias será el de "recoger", "unir", volver a crear la cohesión perdida por la acción de los soldados israelíes. Esa participación total de las familias en la recolección de sus cuerpos es la misma que se muestra en la repartija del toro sacrificado. Es el mismo gesto pero con fuerzas inversas: en uno se reparte para unir y en el otro se recoge para unir. El centro de ambas acciones es la concepción social de un cuerpo colectivo que les pertenece a todos: la carne del animal les pertenece a todos; los cuerpos mutilados de sus seres queridos también.

\section{CUERPO Y COHESIÓN SOCIAL}

Toda masacre, aunque tiene como fin último la muerte del otro, pareciera ser más que esa mera muerte. Sin duda, el cuerpo y su materialidad, su modo de ocupar un espacio concreto y de permanecer más allá de la muerte es un tema central en una masacre. La masacre es 
un hecho colectivo que se infringe sobre un gran número de personas y que afecta la corporalidad de estos. Una vez cometida la masacre: ¿qué se hace con los cadáveres? El anonimato o pérdida del nombre de la víctima es otro rasgo central de una masacre. Es imposible o difícil mantener el nombre de cada víctima, más bien se conserva una cantidad $\mathrm{x}$ de sujetos en la memoria: 275. Este hecho inherente a la masacre, esta colectividad que prima sobre la singularidad y la permanencia de los cuerpos aún más allá de perpetrado el hecho mismo será objeto de nuestro estudio. Sostenemos que tanto la colectividad como la permanencia de los cuerpos cobran en Notas un rol central dentro de la estética visual de Joe Sacco.

Primeramente cabe destacar la importancia del cuerpo en la sociedad palestina como elemento generador de identidad y cohesión. David Le Breton en la Sociología del cuerpo afirma: "En las sociedades que todavía siguen siendo relativamente tradicionales y comunitarias, el 'cuerpo' es el elemento que liga la energía colectiva" (2002: 32). Es importante comprender que el cuerpo en Notas ocupa un rol fundamental a la hora de testificar las matanzas, aunque este rol no se entienda de modo aislado. Mucho más, hemos de entenderlo como fungiendo un peso social dentro de la comunidad. Dicho peso continúa más allá de la muerte como un rasgo propio de la comunidad palestina. Habremos de mostrar cómo Sacco privilegia esa centralidad del cuerpo para su testimonio, pero siempre entendiendo que este cuerpo forma parte de un todo mayor. Siguiendo a Le Breton, parece evidente que el uso del cuerpo para los palestinos se entiende dentro de una estructura social comunitaria: "En las sociedades comunitarias, en las que el sentido de la existencia del hombre implica un juramento de fidelidad al grupo [...] el cuerpo no existe como un elemento de individuación" (2002: 22). En ese sentido, nuestra lectura de lo corporal en Notas es la de un sistema premoderno y basado aún en tradiciones populares: "El cuerpo de la modernidad, resultado de un retroceso en las tradiciones populares y de llegada del individualismo occidental, marca la frontera entre un individuo y otro, el repliegue del sujeto sobre sí mismo" (2002: 23). Este cuerpo comunitario se muestra en Notas, incluso sin ligarlo aún al problema de las matanzas, en tres aspectos centrales: la importancia de la familia extendida, la mujer-madre como cohesionadora y la casa como espacio de reunión social fundamentalmente ligada a las comidas. Veamos un ejemplo de viñeta para cada uno de estos aspectos. 
Preponderancia de la familia extendida (2009: 174): la gran mayoría de las entrevistas de Sacco suelen acontecer en presencia de la totalidad de la familia y esto comprende tres generaciones: abuelos, hijos y nietos. Un ejemplo de esto lo vemos en el relato de Zaki (2009: 174). En la tercera viñeta se observan los rostros asustados de todos los miembros de una familia: en un primer plano la boca arrugada del abuelo, al medio la madre con su hija en brazos y a un costado otro niño.

La importancia de la mujer (2009: 359): la mujer en Notas tiene dos funciones centrales. Es la que busca el cadáver de su pariente muerto o desaparecido y es la que llora. Ambas funciones son vitales para la cohesión social: enterrar a los muertos permite la memoria y el llanto es el reconocimiento de esa vida como vida perdida (Butler, 2010: 21). El llanto de las mujeres está presente como una gestualidad altamente codificada. Consideramos el llanto como una técnica corporal, tal y como lo entiende Le Breton: "considerados como gestos codificados para obtener una eficacia práctica o simbólica, se trata de modalidades de acción, de secuencias de gestos, de sincronías musculares que se suceden para obtener una fidelidad precisa" (2014: 41). Sacco dedica varias viñetas a la técnica corporal del llanto, el que a veces incluye el tirarse arena a la cabeza, acompañado por gritos. El llanto de las mujeres actúa también como efecto de contraste con la frialdad de los soldados israelíes.

La casa como espacio de reunión y de comida (2009: 202): así como el espacio de las masacres es la calle y su apertura, la familia se reúne en la casa. La casa palestina es pobre y consiste, más que en muebles, en la presencia misma de los miembros de la familia sentados en el suelo. Dos son los momentos de reunión: la comida y el relato. Muchas veces van de la mano. También se refuerza con la ceremonia del té, dado que genera una fuerte cohesión y es, de hecho, el inicio para varias de las "encuestas" de Sacco.

Ahora bien, nos hemos detenido hasta aquí para mostrar la sociedad palestina de Gaza como una colectividad tradicional en la que los cuerpos fungen un rol central en la cohesión de la comunidad. Nuestro propósito es mostrar cómo ese cuerpo, aún en medio de la masacre, continúa siendo un cuerpo colectivo que da coherencia social. En este sentido, y para explicar esta paradoja implícita, traemos a colación el término imagen ambivalente propuesto por Wendy Kozol en Distant Wars Visible. Kozol explica la ambivalencia del siguiente modo: 
First, ambivalence refers to the contradictions, tensions, and frictions immanent in representation. Second, I use ambivalence as an analytic to understand how production practices, contexts of circulation, and, more broadly, intertextual discursive practices animate frictional and contingent conditions of witnessing. Visual witnessing is not a one-way mirror but a relational process between the photographer or artists, subjects of the image, viewer, and surrounding contexts (2014: 11-12).

Creemos que las imágenes de los cuerpos cadáveres, cuerpos heridos y cuerpos sometidos de los palestinos se dejan adscribir a esta categoría de imagen ambivalente. Su ambivalencia radica sobre todo en que son el lugar de convergencia de lo positivo y de lo negativo. En ellas converge toda la violencia perpetrada por los soldados israelíes, por un lado, y, por otro, todo el amor y solicitud de sus familiares por llorarlos y recogerlos. Son testimonio del horror de un conflicto, pero simultáneamente de la alta cohesión social de un grupo cultural y racial como los palestinos de la franja de Gaza. Retomemos lo que afirmábamos en un comienzo sobre los rasgos propios de una matanza: permanencia y modo de ocupar un espacio. Apoyándonos en los postulados de Judith Butler, entraremos ahora en el análisis de algunas viñetas concretas.

Judith Butler, en Cuerpos aliados y lucha política. Hacia una teoría performativa de la asamblea (2017), recalca la función de los espacios públicos en la configuración de un cuerpo político de resistencia. En ese sentido, es singular lo que ocurre en las matanzas que investiga Sacco, ya que ambas ocurren en espacios públicos y a plena luz del día. Estos son: la arteria central del pueblo (Sea Street) y la escuela en donde reúnen a los hombres. Para el análisis nos centraremos en la matanza de Rafah, que es la que Sacco logra reconstituir con increíble precisión y verismo. Lo paradójico aquí es que es el llamado de los israelíes el que hace que los palestinos se constituyan como cuerpo de lucha, son ellos los que conforman a ese otro en su performatividad escénica. Butler sostiene: "En las calles y plazas de las ciudades tienen lugar manifestaciones multitudinarias que en los últimos tiempos son cada vez más frecuentes [...]. Los cuerpos se reúnen, se mueven y hablan entre ellos" (2017: 75). Lo que ocurre en la matanza de Rafah es que los cuerpos "son reunidos", los cuerpos "son 
movidos". De ahí que sean imágenes ambivalentes, ya que la reunión no es voluntaria sino convocada por parlantes. Sin embargo, para el efecto de esa imagen, de esa visualidad que Sacco reconstruye con su gráfica, son igualmente cuerpos que se constituyen en una multitud que se mueve y opera como un cuerpo en masa. Es un cuerpo político hecho visible por los israelíes, son ellos los que arman ese cuerpo convertido en cientos de hombres que se desplazan por la calle principal, entran a la escuela pública del pueblo y se congregan en el patio de ésta. Sobre este punto queremos centrar el análisis de las imágenes de Sacco. Sacco privilegia esa apertura, esos cuerpos reunidos y el peso de esa visualidad. Seguimos aquí a Butler en el capítulo "Nosotros, el pueblo": ideas sobre la libertad de reunión" en Cuerpos aliados y lucha política. En este ensayo, Butler sostiene que lo que constituye comunidad, más que un lenguaje, es la praxis misma de la reunión. Compartir un determinado espacio es en sí mismo lo que fundamenta la existencia de un determinado grupo. Postulamos que todo el recorrido por la calle Sea Street, todo el movimiento de los cuerpos de hombres palestinos, dirigidos y finalmente concentrados en el patio de la escuela, conforman un nosotros de enorme fuerza y sentido político. La ambivalencia es clara, estos hombres no ocupan ese espacio público por voluntad propia. Sin embargo, y siguiendo a Butler, la presencia ocurre igual. Constituyen comunidad sin necesidad del uso del lenguaje. Esa es la tesis básica de Butler, se constituye comunidad no por el lenguaje sino por la presencia corporal: "Si el lenguaje no siempre denomina y conforma al pueblo como si fuera una unidad, entonces, es que este se manifiesta con ayuda de otros recursos corporales, a través del silencio, del movimiento conjunto, de las plantadas y de ese persistente agrupación de los cuerpos en el espacio público" (2017: 158). Quiero mostrar ahora cómo se presenta ese cuerpo en el espacio público tanto de la calle como de la escuela, y cómo a pesar de la obligatoriedad, o más allá de ella, o por ella misma, estos cuerpos son un nosotros palestinos que actúan con una fuerza comunitaria. Butler sostiene que hay un otro modo de expresarse propio de los cuerpos, que no pasa por el lenguaje. Precisamente, ya que los hombres palestinos son forzados a juntarse y no pueden hablar, cobra valor ese otro modo: "Pero antes que un grupo empiece a plantearse ese lenguaje, hay una alianza de cuerpos que, por así decirlo, se expresa de otro modo" (2017: 159). Cabe preguntarse: ¿cuáles son esos gestos, esas infraestructuras, esas inacciones sostenidas que crean alianza durante la 
masacre de Rafah? Tomamos literalmente la pregunta de Butler para el caso de la matanza de Rafah: ¿Cuáles son las condiciones corpóreas de la enunciación del "Nosotros, el pueblo"? (2017: 178).

Comencemos en orden desde el inicio del relato de la masacre: "Fue un día inolvidable", "12 de noviembre de 1956" "lo tengo grabado en la memoria", "era un lunes" "Los judíos ordenaron por los altavoces que todos los hombres entre 15 y 60 años se reunieran en la escuela" (2009: 205). Así comienza el relato verbal. Vamos ahora a las condiciones corpóreas: la primera de ellas es el caminar, la larga caminata con las manos en alto desde las respectivas casas por la calle central del pueblo. Visualmente la ropa o la indumentaria también será decidora, mantos largos, la cabeza con turbante y las babuchas. Si bien Sacco muestra los rostros, también se hará énfasis en las piernas, las manos en alto y en los pies. Los pies son representados en numerosas viñetas de enfoque medio para mostrar cómo pierden sus babuchas y son obligados a marchar a pie descalzo. Los pies descalzos son un fuerte elemento unificador de ese cuerpo violentado, lo mismo que las chalupas que van siendo dejadas como reguero en el camino.

A partir de la página 217 (2009: 217), Sacco comienza a usar el enfoque desde lo alto. La perspectiva es la de un dron que da cuenta de los desplazamientos de los hombres desde sus casas y su marcha por la avenida central del pueblo. Esta perspectiva genera varios efectos difíciles de describir. Por un lado, se capta la magnitud del evento, la violencia de los soldados; por otra, la obediencia y orden de los palestinos. La imagen recuerda al recorrido del toro en el "Festín" y el asedio de los niños. Los hombres caminan con los brazos en alto y sus cuerpos generan sombras lo que da cuenta del suceso cometido a plena luz del día. También se observa la pérdida de las babuchas y como éstas van quedando regadas por el camino. La técnica de altura genera una cierta miniaturización de los involucrados, como si fueran soldaditos de plomo y figuritas de plástico puestas en una escenografía reconstructiva. La miniaturización genera distancia pero, al mismo tiempo, permite la creación de la multitud como una figura de ganado que es cruelmente arreado. En la página siguiente (2009: 218) una viñeta alargada muestra un acercamiento a esa misma caravana de hombres con sus manos en alto y se perciben rostros y, a lo lejos la densa fila que se pierde en la calle y la lontananza. Sacco da cuenta así de la magnitud del evento: los cuerpos están pegados el uno al otro 
sin espacios entre ellos. En las páginas 220 y 221 (2009: 220-221) Sacco va integrando nuevas técnicas. Hace un giro en la perspectiva y baja a nivel de los cuerpos concretos. Esta vez se trata de un encuadre medio pero desde la espalda de un grupo de hombres caminando con sus manos alzadas. Las manos alzadas y la cabeza gacha será la imagen que más se repetirá, convirtiéndose en una condición corpórea. Sin embargo, la viñeta en cuestión exacerba la colectividad mediante la disposición grupal en forma casi de triángulo en la que los hombres se forman unos sobre otros. Sacco monta las manos de los hombres sobre las espaldas y cabezas de los que les preceden y se refuerza la sensación de batallón inseparable. En esta viñeta ya se anuncia sutilmente la opción final de Sacco de involucrar al lector en esa marcha mortal. Gracias a la perspectiva de espaldas, el lector parece ir siguiendo al grupo de hombres.



Figura 1. Hombres caminando de espaldas (2009: 220)

A la condición corpórea de la marcha se le añadirá la de los cuerpos puestos en hilera de espaldas contra el muro de la escuela. La hilera se prolonga y se convierte en otro modo de patentizar la colectividad. Uno de los testigos relatará mediante el plural: "Nos quedamos frente al muro", "marchábamos a lo largo del muro, paso a paso" (2009: 226). Una vez al interior del patio de la escuela se presentarán las imágenes más fuertes en relación a la unidad corporal y la disposición de los cuerpos. Aquí, nuevamente, serán las opciones gráficas de Sacco y no el mero relato verbal las que generarán ese efecto. La visión desde arriba ya mencionada más un punto de fuga en la lontananza caracterizan las viñetas del patio de 
la escuela. Un testigo relata: "Había mucha gente. -¡Una nación entera!en el suelo de la escuela" (209: 263). Y la viñeta muestra a los hombres acuclillados con las manos en la cabeza formando una masa compacta, hilera tras hilera, sin espacio alguno entre cada uno de ellos. Una sola masa, en la que, no obstante, se distinguen cada una de las figuras. Hay sujeto y hay un cuerpo mayor en la sumatoria de esos individuos puestos ordenadamente uno al lado del otro. Extrañamente, esa posición corporal "obligada" es también la posición que el palestino asume cotidianamente al orar, al sentarse en la alfombra de su casa. Pareciera que en esa urgencia de los soldados israelíes por darles un orden, el palestino asume automáticamente una postura cultural que le ayuda, precisamente, a enfrentar esa condición como sujeto comunitario. La verbalización de los testimonios refuerza nuevamente ese sujeto colectivo desde una vivencia corpórea cultural que es esa manera de sentarse: "Nos sentamos así [...] de esta manera" (2009: 265). En ese sentarse de una determinada manera vemos un gesto que va más allá de la entrega pasiva, un esbozo de resistencia como la entiende Butler: "la resistencia tiene que mostrar las dimensiones abandonadas o no sostenidas de la vida, pero además hay que movilizar la vulnerabilidad como una forma deliberada y activa de resistencia política" (2017: 185). Quizás sería ir muy lejos al hablar de resistencia política en la condición corpórea de acuclillarse todos juntos, pero al menos un volverse a lo más propio de ellos, tal como afirma un testigo: "Nos consagramos a Dios" (2009: 264). Los palestinos estuvieron horas y horas sometidos a esa postura, y es aquí en dónde rescato esa condición corpórea con la idea de la resistencia. Tal como lo sugiere Butler: "La resistencia no violenta necesita de un cuerpo que aparezca, que actué, y que con sus acciones quiera dar forma a un mundo distinto de aquel que combate" (2017: 188). Conecto con el relato testimonial ya mencionado, Abel Hadi sostiene: "Hombres desarmados contra un poderoso ejército ¿Qué podíamos hacer?” (2009: 264). Probablemente nada, al menos entendido como un ataque o respuesta directa. Sin embargo, leemos su manera de sentarse todos juntos como ese "querer dar forma a un mundo distinto al que combate". Sacco insistirá en la representación de esta postura a lo largo de varias viñetas, si obviáramos a los soldados israelíes la postura no difiere mucho de la de un enorme grupo de hombres musulmanes orando. 


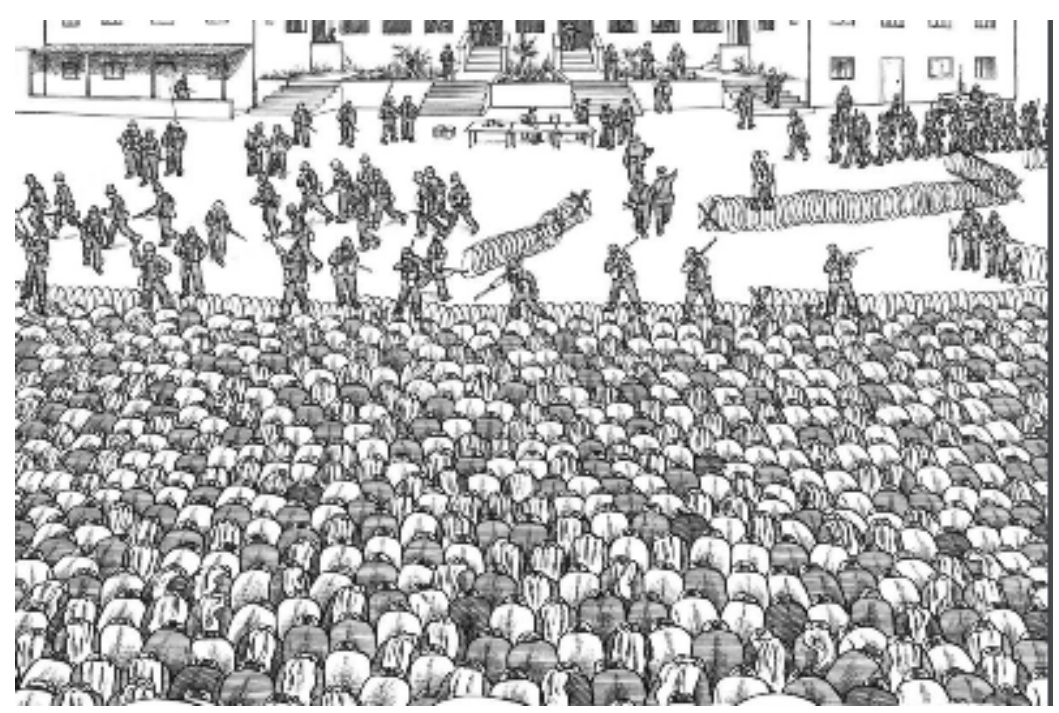

Figura 2. Hombres sentados en la escuela (2009:301)

Por último, a las condiciones corpóreas ya señaladas, habría que pensar la función indicial de las babuchas que van quedando en el camino. Sacco recurre a viñetas más pequeñas y de primer plano para marcar repetidamente este regadero de babuchas. Una vez más, las babuchas y los pies descalzos corresponden a la categoría de imagen ambivalente o de doble signo. Las babuchas están por todas partes, aparecen en casi todas las viñetas como una señal de la violencia ejercida por los soldados, pero también puede leerse como la persistencia del sujeto. No son metáfora, son metonimia, están en el lugar del palestino vapuleado. Por otro lado, y aquí volvemos a la idea de gesto como rasgo cultural imposible de separar de un uso, la ausencia de la babucha la podemos conectar al musulmán religioso. El musulmán se quita los zapatos antes de entrar a la mezquita y también suele hacerlo al entrar a su casa como medida de higiene. Es así como el descalzarse en un momento se realiza como un gesto: "En la puerta de la escuela había un gran número de zapatos. Los que llegaban pensaban que tenían que quitarse los zapatos [...]. Yo me quité los zapatos" (209: 241). Así, los zapatos abandonados y amontonados son señal de violencia y al mismo tiempo de resistencia no violenta. Ese gesto cultural nos devuelve a ese mundo distinto de los palestinos que quiere ser combatido por los israelíes sin lograrlo. Las babuchas abandonadas son la persistencia de la 
cultura musulmana.

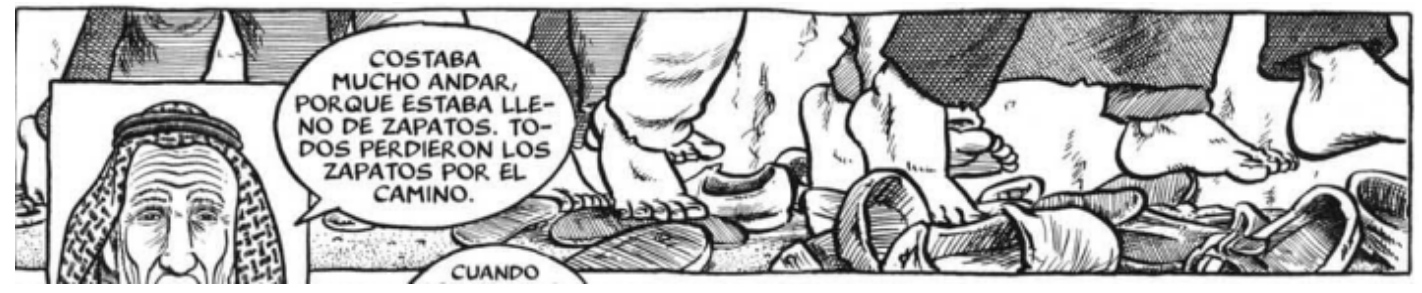

Figura 3. Babuchas esparcidas (2009: 229)

\section{CUERPOS CADÁVERES}

Sacco entra de lleno en la masacre al mostrar directamente los efectos de ella. No elude este punto central que es el núcleo testimonial e histórico: la cantidad de hombres asesinados ese día de noviembre de 1956. Sacco asume visualmente toda la violencia de la masacre y sus resultados: hombres heridos, hombres muertos y sangrantes, cuerpos abandonados, órganos internos repartidos. Queremos ahora pensar tanto la representación de esos muertos como sus posibles alcances al interior de un texto que tiene como eje el testimonio. Nos preguntamos: ¿Qué función cumple el cadáver al interior del testimonio? En términos generales proponemos leer el cadáver como la persistencia del cuerpo, su enconada negativa a desaparecer y por eso mismo como signo con fuerte carga indicial: esto ha sucedido, esto sucedió (Barthes, 1989: 136). El cuerpo muerto es también doble o ambivalente ya que es depositario de la violencia ejercida y testimonio en sí mismo de esa violencia. Una anécdota de Primo Levi en relación a su número tatuado por los nazis ejemplifica esta ambivalencia del signo-cuerpo. El tatuaje es al mismo tiempo horror y testimonio inseparable. Los cadáveres serán también motivo de conflicto entre ambos bandos: los soldados que quieren hacerlos desaparecer y así eliminar toda huella de la matanza y los palestinos que quieren recogerlos e integrarlos a sus ritos de entierro. La matanza se basa en la pérdida de la individualidad. Cada uno de los asesinados se ve sumergido por la totalidad, el número final: 275 muertos. El rescate de ese cadáver es un intento de restitución del nombre único al interior de esa masa anónima. Vamos ya a la pregunta 
central: ¿Cómo se representan los cadáveres?

Una de las técnicas preferidas en la representación de los cadáveres es la de mostrar los cuerpos enteros. La postura suele ser la de cuerpos que yacen tendidos en el suelo y se ven los rostros de los muertos. Muchos rostros conservan como rictus final en la boca la señal del dolor extremo. A veces boca arriba, otras, boca abajo mostrando las heridas a bala y la sangre chorreante. Llama la atención el uso de las manos y su singular expresión.

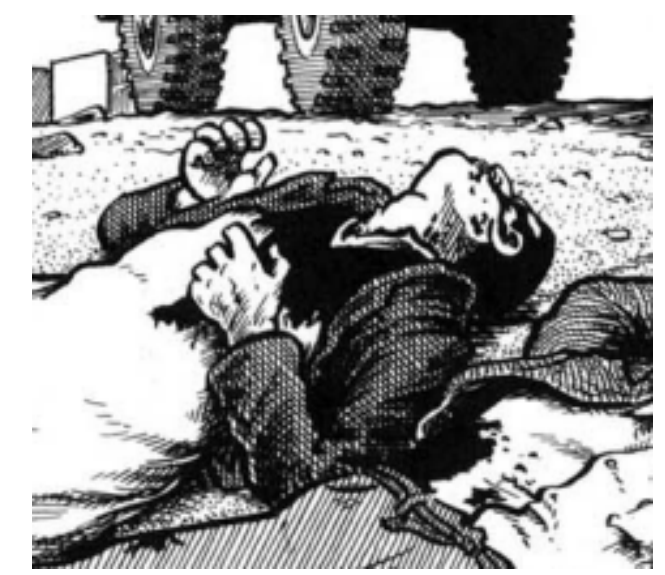

Figura 4. Manos agarrotadas (2009: 334)

Las manos son en la gráfica de Sacco un elemento que contribuye a una visualidad háptica y casi un sello personal del autor. Así lo sostiene Rebeca Scherr en su artículo "Shaking Hands with Other People's Pain: Joe Sacco's Palestine": "hand imagery becomes a reminder of the materiality of the author's body: a trace there is 'really' a person who holds, narrates, and feels; a link to life beyond the text" (2013: 22). Ahora bien, nos preguntamos por la insistencia en las manos de los cadáveres. Éstas tienen una y otra vez la misma posición: rígidas, agarrotadas y duras. No hay descanso en esos cuerpos, la tensión en ellos es evidente. Los cuerpos no yacen blandos o flácidos en el suelo. Por el contrario, se trata por lo general de cuerpos duros, fijos en una posición. Aquí el dibujo de Sacco se torna más hacia el trabajo fotográfico, ya que es como si estuviera captando un momento concreto del cuerpo muerto. Saco opta claramente por el gesto del rigor mortis; son cadáveres pesados, densos, con las manos semialzadas y como pidiendo o reclamando algo. El rigor mortis otorga al 
cadáver un especial poder de atención, por lo que adquiere una presencia muy consistente debido a esta dureza. Los cadáveres parecen así reclamar o solicitar en su presencia endurecida una determinada respuesta. Sin duda su primer reclamo es el de ser mirados. Los cadáveres de Sacco reclaman la mirada del lector. Sobre todo sus manos crispadas, manos de hombres fuertes y grandes. Las manos de Sacco tienen una fuerte reminiscencia con otras manos pictóricas. Nos traen a la mente las manos de los cuerpos destrozados de El Guernica de Picasso, las manos alzadas de El 3 de mayo en Madrid de Goya. Son manos toscas, de grandes dedos, de hombres de trabajo. Las manos, al igual que las babuchas abandonadas en el camino hacia la escuela, parecieran cobrar cierta independencia. Ellas claman hacia el cielo, se conectan con una serie de gestos ya advertidos anteriormente: el dolor punzante de las mujeres que alzan las manos como exigiendo a Dios y las manos alzadas ya descritas durante la matanza. Las manos del rigor mortis son así un clamor a Dios, un testimonio de ese cuerpo que habla aún más allá de su muerte. Un testigo relata cómo se topa con una fosa llena de cuerpos a medio enterrar, el dibujo de Sacco (2009: 352) muestra un rostro semi-hundido y unas manos que aparecen en medio de la tierra. Es decir, una vez más, las manos apareciendo como gesto de humanidad y demanda de justicia. Finalmente, el ciclo de la matanza se cierra con la recuperación de los cadáveres por parte de los deudos y la sepultación de estos. Las imágenes más potentes de entierro las tenemos en el amontonamiento de los cadáveres uno sobre otro por un tema de espacio en mausoleos. Se relata: "los mezclamos todos. Pusimos cuatro o cinco cuerpos dentro de una fusgeya... unos encima de otros" (2009: 358). La viñeta del amontonamiento está notablemente lograda en su patetismo. Sacco maneja el contraste de luz y sombra. La luz que entra por la tapa abierta y los hombres que sostienen a los cuerpos que van entrando a la oscuridad de la tumba. Los cadáveres ya pesan y debajo de ellos se observan los muertos previos ya convertidos en calaveras. Es un notable descenso de cuerpos en el que se entremezclan mórbidamente las calaveras antiguas, los muertos de la matanza y los vivos que con esfuerzo y en contacto cuerpo a cuerpo van entrando a los pesados hombres. Hombres muertos que delatan en sus rostros y en sus manos duras las circunstancias violentas de sus muertes. En esta viñeta reconocemos cierta intericonocidad ${ }^{3}$ con el motivo

${ }^{3}$ El concepto intericonicidad lo tomamos de Clément Chéroux quién lo propone "para evocar estas 
ampliamente trabajado en la pintura del descendimiento de Cristo de la cruz. Hay juego de luz y sombras y hay una complicidad de cuerpos entre los que descienden y los que son descendidos.

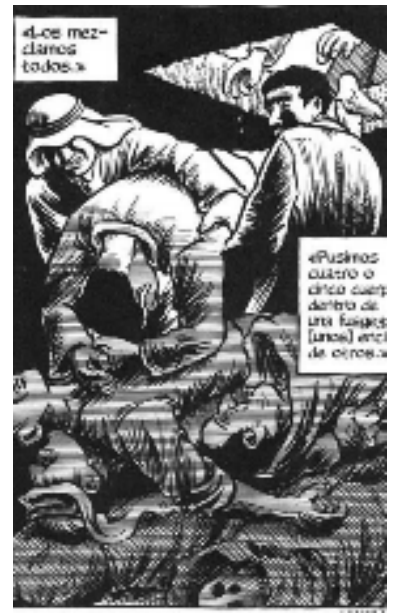

Figura 5. Cuerpos son bajados a la sepultura (2009: 358)

\section{CONCLUSIONES}

Hemos querido mostrar la preponderancia que la representación del cuerpo tiene en el trabajo testimonial gráfico de Joe Sacco en Notas al pie de Gaza. Los testimonios que Sacco va recogiendo en su minuciosa labor de periodista gráfico son, sin duda, lo que organiza la narración de Notas en cuanto texto de denuncia. Sin embargo, al ser Notas una novela gráfica es vital comprender la función de la visualidad que específicamente se concentra en la mostración de los cuerpos. Ya que la violencia se ha ejercido sobre esos cuerpos, quisimos centrarnos en el trabajo concreto que Sacco hace mediante ellos. Distinguimos tres modalidades de trabajo: la fórmula cinegética, las condiciones corpóreas mediante las que se constituye la comunidad y la persistencia de los cadáveres.

La fórmula cinegética se utiliza en el aparente desconectado capítulo el "Festín". Tal como mostramos, la matanza del toro se convierte 
en una metáfora central para graficar la violencia y la desmembración cometida sobre el pueblo palestino. En un segundo uso, nos apoyamos en las recientes teorías de Judith Butler sobre la constitución de comunidad mediante la corporalidad. Aquí reconocimos, a lo largo de la matanza, las siguientes condiciones corpóreas: la caminata con los brazos alzados, los hombres puestos en hileras y una determinada manera de acuclillarse. Es mediante estos gestos que, más allá de la violencia de la reunión, surge la comunidad palestina como posible sujeto de resistencia. Las babuchas desperdigadas por el camino fungen también como metonimia del cuerpo palestino violentado. Para finalizar, consideramos la representación de los cuerpos cadáveres como un recurso extremo de Sacco para testimoniar sobre las matanzas de 1956. En los cadáveres resaltamos la opción por el rigor mortis $\mathrm{y}$, sobre todo, la denuncia mediante las manos rígidas y alzadas.

En los tres usos destacamos el aporte significativo que Sacco logra imprimir a su denuncia mediante el cuerpo. La novela gráfica se convierte así en un potente medio para transmitir, más allá del contenido estrictamente informativo, un hecho de enorme dramatismo y complejidad como fueron las matanzas de Rafah y Khan Younis.

\section{REFERENCIAS BIBLIOGRÁFICAS}

BARTHES, R. (1989). La cámara lúcida. Nota sobre la fotografía. Barcelona: Paidós.

BURUCÚA, J. E. y KWIATKOOWSKI, N. (2014). “Cómo sucedieron estas cosas". Representar masacres y genocidios. Buenos Aires: Katz Editores.

BUTLER, J. (2017). Cuerpos aliados y lucha política. Hacia una teoría performativa de la asamblea. Barcelona: Paidós.

(2010). Marcos de guerra: las vidas lloradas. Buenos Aires: Paidós.

CHEROUX, C. (2013). “QQué hemos visto del 11 de septiembre?”. En Cuando las imágenes tocan lo real, G. Didi-Huberman (ed.), 3968. Madrid: Círculo de Bellas Artes.

EARLE, H. (2017). Comics, trauma, and the new art of war. Jackson: University Press of Mississipi.

KOZOL, W. (2014). Distant Wars Visible. The Ambivalence of Witnessing. 
Minneapolis: University of Minnesota Press.

(2012). "Complicities of Witnessing in Joe Sacco's Palestine". En Theoretical Perpectives on Human Rights and Literature, A. Schultheis \& E. Swanson (eds.), 165-179. New York: Routledge.

LE BRETON, D. (2002). La sociología del cuerpo. Buenos Aires: Nueva Visión.

MAC-MILLAN, M. (2019). "Notas al pie de Gaza de Joe Sacco: un historiador a contrapelo (anacronía y memoria)". Revista de Humanidades UNAB 39, 207-234.

ROMERO-JODAR, A. (2017). The trauma graphic novel. New York: Routledge.

SACCO. J. (2009). Notas al pie de Gaza. Barcelona: Mondadori.

SCHERR, R. (2013). "Shaking Hands with Other People's Pain: Joe Sacco's Palestine". Mosaic: A Journal for the Interdisciplinary Study of Literature 46.1, 19-36.

(2015). "Framing human rights: comics form and the politics of recognition in Joe Sacco's Footnotes in Gaza". Textual Practice 29.1, 111-131.

SHAY, M. (2014). "Framing refugee time: perpreted regression in Joe Sacco's Footnotes in Gaza". Journal of Postcolonial Writing 50.2, 202-215.

VERSACI, R. (2007). “The New Journalism Revisited”. En This book contains graphic language, 109-135. New York: Continuum International Publishing Group.

WORDEN, D. (ed.) (2015). The comics of Joe Sacco: journalism in a visual world. Jackson: University Press of Mississipi.

WOO, B. (2010). "Reconsidering Comics Journalism: Information and Experience in Joe Sacco's Palestine". En The Rise and Reason of Comics and Graphic Literature: Critical Essays on the Form, Joyce Goggin \& Dan Hassler-Forest (eds.), 166-177. Jefferson, NC: McFarland.

Recibido el 8 de marzo de 2019.

Aceptado el 22 de abril de 2019. 